\title{
A cross sectional study on menstruation and menstrual hygiene among medical students of Valsad, Gujarat
}

\author{
Hinaben R. Patel ${ }^{1}$, Ravikant R. Patel ${ }^{2} *$
}

${ }^{1}$ Department of Obstetrics and Gynecology, GMERS Medical College, Valsad, Gujarat, India
${ }^{2}$ Department of Community Medicine, GMERS Medical College, Valsad, Gujarat, India

Received: 22 September 2016

Accepted: 18 October 2016

\author{
*Correspondence: \\ Dr. Ravikant R. Patel, \\ E-mail: drravi909@yahoo.com
}

Copyright: ( ) the author(s), publisher and licensee Medip Academy. This is an open-access article distributed under the terms of the Creative Commons Attribution Non-Commercial License, which permits unrestricted non-commercial use, distribution, and reproduction in any medium, provided the original work is properly cited.

\begin{abstract}
Background: In many developing countries, a culture of silence surrounds the topic of menstruation and menstruation related issues, as results many young girls lack appropriate and sufficient information regarding menstruation and menstrual hygiene. This may result in incorrect and unhealthy behavior during their menstrual period So, Good hygienic practices such as the use of sanitary pads and adequate washing of genital area are essential during menstruation.

Methods: A cross sectional study conducted among medical students of GMERS Medical College, Valsad. A total 203 girls of first, second and third MBBS medical students between age group of 16-22 years were participated in this study. Data was collected by using pre-designed, pre-tested Questionnaire. The data was entered and analyzed by using Microsoft excel 2010 and appropriate statistical test were applied.

Results: Out of 203 Girls 84.24\% girls had knowledge about menstruation before they experienced first menstruation (menarche) and Mother was found to be the main source of information. Mean age of menarche was 14.5 years. $86.70 \%$ girls use sanitary napkins where as $13.3 \%$ girls use clothes and reuse them. Most of the girls perceive that sanitary napkin is comfortable and cause adequate absorption but having disadvantage of an expensive and not being easily available at all places.

Conclusions: Menstrual hygiene is a vital aspect of health education for all adolescent girls as it related with health consequences. More number of girls in the urban area was using commercially available sanitary pads as compare to the rural girls. To improve the menstrual hygiene among adolescent girls sanitary napkins should be made universally available at affordable price.
\end{abstract}

Keywords: Medical student, Menstrual hygiene, Menarche, Sanitary napkin

\section{INTRODUCTION}

According to United Nations Children does Emergency Fund (UNICEF) there are 243 million adolescents comprise $20 \%$ of the total population of India which clearly shows that India is truly "young". 1 This sheer number itself is a big challenge in itself 15-19 years constitute $10 \%$ and majority lives in rural areas. Special health care needs and requirements of women during monthly cycle of menstruation are collectively given the term "Menstrual hygiene". 2 Menstruation hygiene is an issue that every girl and women has to deal with in her life but there is lack of awareness on the process of menstruation. The first menstruation also called as 'MENARCHE'. Menarche marks the beginning of a multitude of physical, physiological, and psychological changes in the lives of the adolescent girls. Menarche is one part of the maturation process, but it is often, culturally defined as the indicator of girl's maturity and readiness for marriage and sexual activity. Although menstruation is a natural process, it linked with several misconception and practices, which sometime result in 
adverse outcomes. ${ }^{3}$ Menstruation is still regarded as something unclean or dirty in Indian society and it is strongly related with misconceptions and cultural restrictions. ${ }^{4}$

Issues associated with menstruation are never discussed openly and this burden young girls by keeping them ignorant of this biological function.

Till now, the poor menstrual hygiene in developing countries has been an insufficiently acknowledged problem. Researches confirm that with safe menstrual hygienic practices adolescents girls were less vulnerable to reproductive tract infections (RTIs). ${ }^{6}$

Most of the time adolescent girls are unprepared in terms of knowledge, skill and aatitude for managing the menstrual cycle. ${ }^{5}$ In a study among adolescent, only about $60 \%$ girls had partial awareness about adolescent physical changes and menarche. They may also have unsaid anxieties and apprehensions and are subjected to social taboos and restraint during their periods. ${ }^{7}$

Several studies documented that menstruation related problems, had affected more than a third of student's class concentration, participation, socializing with friends, test taking skills and homework task performance. Dysmenorrhea was significantly associated with school absenteeism and decreased academic performance, sports participation, and socialization with peers. $^{8,9}$

Majority of studies were conducted among the adolescent school girls of different population. So present study was conducted to see the knowledge, attitude and practice among medical students regarding menstruation and menstrual hygiene.

\section{METHODS}

A cross sectional study was conducted among $1^{\text {st }}, 2^{\text {nd }}$ and $3^{\text {rd }}$ year of MBBS medical students of GMERS Medical College-Valsad from period of July-2015 to Septmber2015.

The purpose of the study was explained to the students and informed consent was obtained from the girls for participation in this study.

Complete information on individual background, knowledge, awareness, sources of information and practice regarding menstruation and menstrual hygiene were collected from $1^{\text {st }}, 2^{\text {nd }}$ and $3^{\text {rd }}$ year of MBBS students in predesigned pretested Performa with following exclusion criteria.

\section{Exclusion criteria}

- Those Girls who were absent at the time of survey
- Those who were not willing to participated in this study or incompletely field questionnaire were excluded from the study

- Girls who don't have menarche or those having menarche related problems

Total 203 girls were participated in this study after exclusion criteria.

A study also followed by Questions and concerns of participants and education on menstrual hygiene conducted by female faculty of Obstetric and Gaynecology department at the end of session.

No follow up visit were planned to maintain confidentiality of questionnaire and truthfulness of response. Data was entered and analysed by using MS office 2003 and appropriate statistical test were applied.

\section{RESULTS}

Table 1: Demographic profile of medical students.

\begin{tabular}{|c|c|c|}
\hline & Numbers & Percentage \\
\hline \multicolumn{3}{|c|}{ A. Age wise distributions of medical students } \\
\hline Age of students (years) & Numbers & Percentage \\
\hline 16 & 01 & 00.49 \\
\hline 17 & 09 & 04.43 \\
\hline 18 & 53 & 26.11 \\
\hline 19 & 68 & 33.50 \\
\hline 20 & 55 & 27.10 \\
\hline 21 & 13 & 06.40 \\
\hline 22 & 04 & 01.97 \\
\hline \multicolumn{3}{|c|}{$\begin{array}{l}\text { B. A distribution of medical students on the basis of } \\
\text { religion }\end{array}$} \\
\hline Religion & Numbers & Percentage \\
\hline Hindu & 189 & 93.10 \\
\hline Muslim & 10 & 04.93 \\
\hline Other & 04 & 01.97 \\
\hline \multicolumn{3}{|c|}{$\begin{array}{l}\text { C. A Distribution of medical students on the basis of } \\
\text { residential area }\end{array}$} \\
\hline Area of Residency & Number & Percentage \\
\hline Rural & 27 & 13.30 \\
\hline Urban & 176 & 86.70 \\
\hline \multicolumn{3}{|c|}{$\begin{array}{l}\text { D. A Distribution of medical students as per their } \\
\text { mother's education }\end{array}$} \\
\hline Education of mother & Number & Percentage \\
\hline Illiterate & 01 & 00.49 \\
\hline Primary & 11 & 05.42 \\
\hline Secondary & 10 & 04.93 \\
\hline Higher secondary & 38 & 18.72 \\
\hline Graduate & 96 & 47.29 \\
\hline Post-graduate & 47 & 23.15 \\
\hline
\end{tabular}

Total 203 girls from $1^{\text {st }}$ year (61), $2^{\text {nd }}$ year (82) and $3^{\text {rd }}$ year (60) MBBS of GMERS Medical College, Valsad 
were participated in the study and we noted the following observations.

Table 1 shows Demographic profile of medical students, all students were in age group 16-22 years of age and majority of girls were in 18-20 years of age (86.71\%) and mean age of girls were 19 years. Out of 203 girls $93.10 \%$ were Hindu and 86.70 are residing in Urban area.

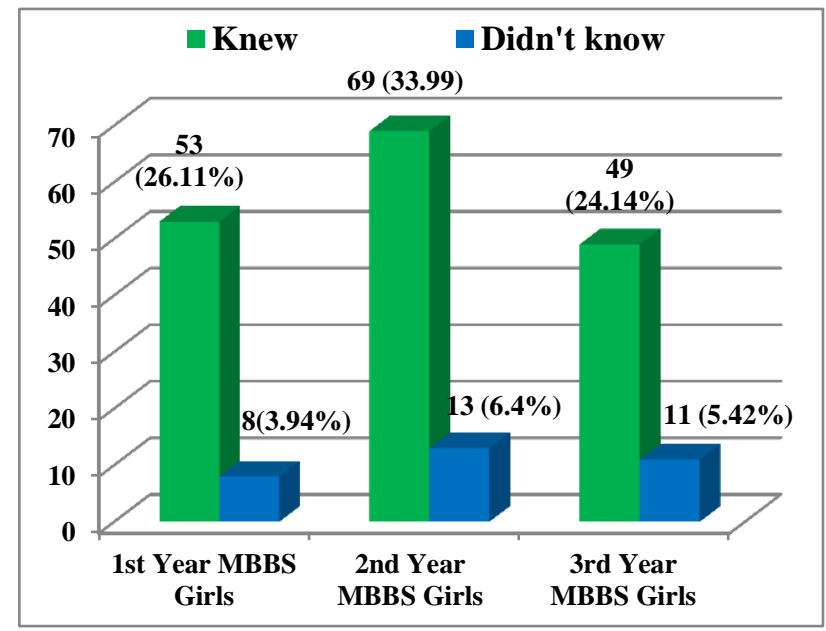

Figure 1(A): Distribution of medical students on the basis of pre-menarchal knowledge.

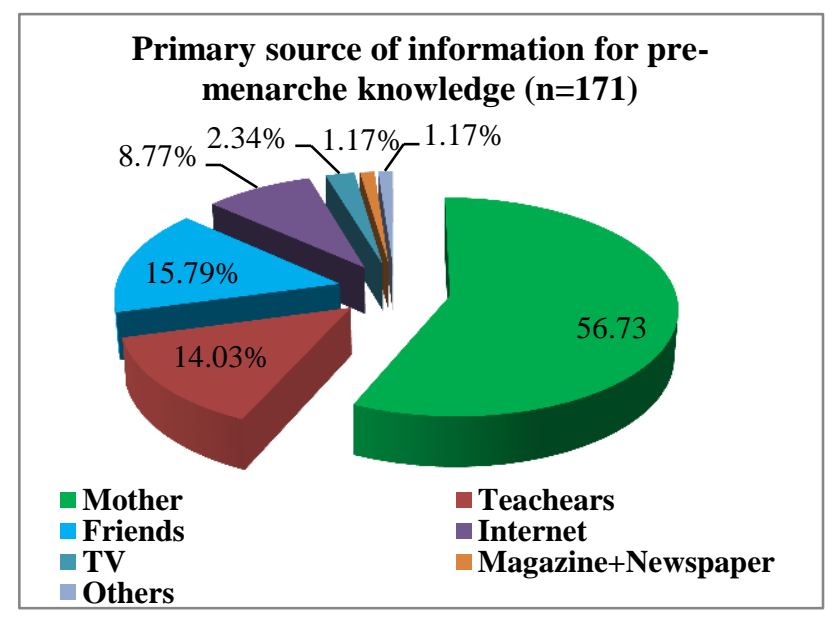

Figure 1(B): A distribution of medical students on the basis of main source of information.

Figure 1(A) shows that out of 203 girls $26.11 \%$ of $1^{\text {st }}$ year, $33.99 \%$ of $2^{\text {nd }}$ year and $24.14 \%$ of $3^{\text {rd }}$ year medical students (Total 84.24\%) had knowledge about menstruation before menarche. The primary source of information for menstruation knowledge was mother $(56.73 \%)$ followed by Friends $(15.79 \%)$, Teacher (14.03\%), Internet (8.77\%), Television (2.34\%) and Magazine (2.34\%) (Figure 1 (B)).

Table 2 shows the relationship between residential area and pre-menarchal knowledge among girls, $86.70 \%$ of girls were from urban area and $13.30 \%$ were from rural area. Out of $20371.43 \%$ of girls belong to urban area had pre- menarchal knowledge as compare to rural area (12.81\%). A Relationship between residential area and pre-menarchal knowledge among girls was statistically significant.

Table 2: Relationship between residential area of students and pre-menarchal knowledge.

\begin{tabular}{|ll|ll|}
\hline $\begin{array}{l}\text { Area } \\
\text { Premenarche } \\
\text { knowledge }\end{array}$ & $\begin{array}{l}\text { Rural } \\
\text { Number } \\
(\boldsymbol{\%})\end{array}$ & $\begin{array}{l}\text { Urban } \\
\text { Number } \\
(\%)\end{array}$ & $\begin{array}{l}\text { Total } \\
\text { Number } \\
(\%)\end{array}$ \\
\hline Knew & $26(12.81)$ & $145(71.43)$ & $171(84.24)$ \\
\hline Don't know & $01(0.49)$ & $31(15.27)$ & $32(15.76)$ \\
\hline Total & $27(13.30)$ & $176(86.70)$ & $203(100)$ \\
\hline
\end{tabular}

Table 3: Distribution of medical students as per their menstrual history.

\begin{tabular}{|c|c|c|}
\hline & Numbers & Percentage \\
\hline \multicolumn{3}{|c|}{ A. Distribution as per age at menarche } \\
\hline Age at menarche (In years) & Numbers & Percentage \\
\hline 11 & 03 & 01.48 \\
\hline 12 & 33 & 16.26 \\
\hline 13 & 55 & 27.10 \\
\hline 14 & 63 & 31.03 \\
\hline 15 & 38 & 18.72 \\
\hline 16 & 09 & 04.43 \\
\hline 17 & 01 & 00.49 \\
\hline 18 & 01 & 00.49 \\
\hline \multicolumn{3}{|c|}{$\begin{array}{l}\text { B. Distribution on the basis of duration of menstrual } \\
\text { bleeding }\end{array}$} \\
\hline $\begin{array}{l}\text { Duration of menstrual } \\
\text { bleeding (In days) }\end{array}$ & Number & Percentage \\
\hline$<4$ days & 55 & 27.10 \\
\hline 5 days & 108 & 53.20 \\
\hline 6 days & 25 & 12.32 \\
\hline 7 days & 11 & 05.41 \\
\hline 8 days & 04 & 01.97 \\
\hline$>9$ days & 00 & 00 \\
\hline \multicolumn{3}{|c|}{ C. Distribution on the basis of menstrual bleeding } \\
\hline Menstruation & Number & Percentage \\
\hline Regular & 158 & 77.83 \\
\hline Irregular & 45 & 22.17 \\
\hline
\end{tabular}

Table 3(A) Shows that age at menarche of these girls were ranges between 11-18 years of age, the maximum numbers of girls between $13-15$ years $(76.85 \%)$ of age group and mean age at menarche was 14.5 years. Out of 203 girls $18(19.7 \%)$ experienced the menstrual bleeding more than 5 days (Table 3(B)). A longer the duration and amount of menstrual blood loss, greater the risk of iron deficiency anaemia among girls.

Out of 203 girls $86.70 \%$ were using sanitary napkin and $13.3 \%$ were using either cloth or both during their menstrual period. $82.27 \%$ of girls were needed to change 2-4 absorbent during first 2 days of menstruation (Table 4 
A and B). $71.94 \%$ girls were dispose the used absorbent in Public dustbin followed by dispose with domestic refuse $(14.29 \%)$ (Table $4(\mathrm{C}))$.

Table 4: Distribution of medical students as per menstrual hygiene.

\section{Number Parentage}

A. Distribution of students as per type of absorbent use during menstruation

\begin{tabular}{|lll}
\hline A. Type of absorbent used & Number & Parentage \\
\hline Sanitary napkin & 176 & 86.70 \\
\hline Cloth & 07 & 03.45 \\
\hline Both & 20 & 09.85 \\
\hline
\end{tabular}

B. Distribution of students as per number of times absorbent changed in a day

\begin{tabular}{|lll|}
$\begin{array}{l}\text { No. Absorbent change } \\
\text { during first 2 days of menses }\end{array}$ & Number & Parentage \\
\hline 1 & 24 & 11.82 \\
\hline $2-4$ & 167 & 82.27 \\
\hline $5-6$ & 12 & 05.91 \\
\hline
\end{tabular}

C. A distribution of students on the basis of method of disposal of absorbent

\begin{tabular}{|c|c|c|}
\hline Method of disposal & $\begin{array}{l}\text { Number } \\
(\mathrm{n}=196)\end{array}$ & Parentage \\
\hline Bathroom/Toilet & 04 & 02.04 \\
\hline Bury in ground & 11 & 05.61 \\
\hline Public dustbin & 141 & 71.94 \\
\hline With domestic refuse & 28 & 14.29 \\
\hline Other & 07 & 03.57 \\
\hline Not answered & 05 & 02.55 \\
\hline \multicolumn{3}{|c|}{$\begin{array}{l}\text { D. A distribution of students on the basis of cleaning } \\
\text { habit of genital during Menstruation }\end{array}$} \\
\hline Cleaning habit of genital & $\begin{array}{l}\text { Number } \\
\text { (multiple } \\
\text { answers) }\end{array}$ & Percentage \\
\hline Don't clean & 03 & 1.48 \\
\hline During bathing & 92 & 45.32 \\
\hline Every time with toilet & 147 & 72.41 \\
\hline Not answered & 02 & 0.99 \\
\hline
\end{tabular}

Majority of girls had habit of cleaning genital in a day either during bathing or every time with toilet (97.5\%). Out of 198 girls $135(68.18 \%)$ were using soap and water and $63(31.18 \%)$ only water as a cleaning agent for genital. Most of the girls perceive that sanitary napkin is comfortable (88.18\%), cause adequate absorption $(66.50 \%)$ and doesn't stain the cloths $(49.26 \%)$ but only disadvantage is expensive and not available at everywhere.

\section{DISCUSSION}

A lot of studies have been done on practices of menstrual hygiene, but most of them done on rural population or in school girls. There is paucity of this study in medical students to the best of author's knowledge. This study has tried to fill this gap.
Menstrual disturbances are the commonest presenting complaint in the adolescent age group and unhygienic practices during menstruation can lead to untoward consequences like pelvic inflammatory diseases and even infertility. ${ }^{10}$

In present study all students were in age range between 16-22 years of age and majority of girls were in18-20 years of age $(86.71 \%)$. Mean age of girls were 19 years. In Dr. Neelima Sharma et al study among medical students all girls were in age range between 18-26 years, of this $50.56 \%$ girls were in the age group of 18-20 years followed by $34.65 \%$ in $21-23$ years of age group. ${ }^{11}$ In present study $93.10 \%$ were Hindu and 86.70 are residing in urban area.

In present study $84.24 \%$ had knowledge about menstruation before menarche. Dr. Neeelima Sharma et al in their study among medical students in north India found that $67.71 \%$ of student had previous knowledge of menstrual practice before attaining menarche and this result is in accordance with other studies done by Dasupta A et al, (67.5\%) and Juyal R et al (64.5\%) was done in population other than medical student. ${ }^{3,5}$ In study conducted by Rupali Patel at Nagpur and Kalpana Katiyar et al at urban area of Meerut only $55.57 \%$ and $38 . \%$ girls had knowledge regarding menstruation. ${ }^{12,13}$ The higher percentage of pre-manarchal knowledge in our study is due to majority of girls are belong to upper socio-economic class and may be due to increase socialization and increase usage of internet.

In Present study the main source of information regarding menstruation knowledge was Mother $(56.73 \%)$ followed by Friends $(15.79 \%)$, Teacher $(14.03 \%)$, Internet $(8.77 \%)$, Television $(2.34 \%)$ and Magazine (2.34\%) which is similar to study conducted by Dr. Neeelima Sharma et al and Juyal R et al, that source of information was mother $(35.22 \%$ and $31.2 \%)$, friends $(23.29 \%$ and $31.8 \%)$, sister $(22.15 \%$ and $28.1 \%)$, internet $(6.81 \%)$, teachers $(3.40 \%$ and $3.4 \%)$ respectively. ${ }^{5,11}$ Rupali Patel et al, in her study found that the main source of information was mother (33.95\%), elder sister (25.62\%), teacher $(25.31 \%)$ and friend $(15.12 \%){ }^{12}$

In present study $71.43 \%$ of girls belong to urban area had pre-menarchal knowledge as compare to rural area $(12.81 \%)$ and found statistically significant. In contrast to other studies In which awareness among rural girls was significantly higher than urban girls.,

In present study the ages at menarche were ranges between 11-18 years and the mean age at menarche was 14.5 years. Shubhangi Nayak et al, in their study showed the age range between 10-16 years with mean age at menarche was $13.13+1.046 .{ }^{14}$ In Study conducted by Dr. Neelima et al, found the age ranges between 9-17 years with mean age 13 years ${ }^{11}$ which was almost similar to other studies done in different population (urban, rural, and tribal) in various places all over the India. ${ }^{3,5,15}$ In our 
Study $19.7 \%$ girls experienced the menstrual bleeding more than 5 days, $77.83 \%$ of girls have regular menstrual cycle and $22.17 \%$ had irregular menstrual cycle. In Dr. Neelima Sharma et al $57.0 \%$ of girl were having regular menses with moderate blood flow while $43 \%$ of girls reported with irregular menses. ${ }^{11}$

In present study $86.70 \%$ girls were using sanitary napkin and $13.3 \%$ were using either cloth or both during their period which was similar to study conducted by Dr. Neelima Sharma et al in which $86.36 \%$ of girls were using sanitary napkin as absorbent material during their menstrual cycle, while $70.2 \%, 81.73 \%$ and $94.0 \%$ girls were using sanitary napkin as an absorbent in study conducted by Subhangi Nayak et al Madhumita B et al and Adhikari $\mathrm{P}$ et al respectively. ${ }^{11,14,16,17}$

In this study $82.27 \%$ of girls were needed to change 2-4 absorbent during first 2 days of menstruation which was similar to study conducted by Dr. Neelima Sharma et al $72.0 \%$ were changed their pad six hourly. ${ }^{11}$ In present study $71.94 \%$ girls were dispose the used absorbent in Public dustbin followed by dispose with domestic refuse $(14.29 \%)$. In Subhangi Nayak et al study $70.2 \%$ girls were using sanitary pad and $25.6 \%$ were using clean cloth as an absorbent. They noted that $71.94 \%$ girls were disposing the used absorbent in Public dustbin followed by dispose with domestic refuse (14.29\%). $70.2 \%$ of girls wrapped the used absorbent in paper and threw it off. ${ }^{14}$

In present study majority of girls had habit of cleaning genital in a day either during bathing or every time with toilet $(97.5 \%)$ which is in contrast with the study conducted by Dr. Neelima Sharma et al among medical students were only $42 \%$ doing vaginal wash daily. ${ }^{11}$ In our study $68.18 \%$ of girls were using soap and water and $31.18 \%$ only water as a cleaning agent for genital. In study conducted by Dasgupta et al, and Madhumita Bhattacharyya et al found that $97.5 \%$ and $64.74 \%$ of girls cleaned their external genitalia with soap and water regularly during the days of menstruation respectively. ${ }^{3,16}$ Different studies from India and abroad have reported that $34-42.2 \%$ adolescent cleaned their external genitalia with soap and water during menstruation. ${ }^{15,18-20}$

In present study $88.16 \%$ of girls perceived that sanitary napkin is comfortable, $66.50 \%$ perceived that it cause adequate absorption and have only disadvantage is expensive and not easily available at all places. Juyal $\mathrm{R}$ et al, in their study found that availability and affordability being key obstacles to more widespread use of sanitary napkin followed by lack of awareness and lack of disposal facilities. ${ }^{5}$

\section{CONCLUSION}

Improper Menstrual hygiene is important risk factor for reproductive tract infections and is a vital aspect of health education for adolescent Girls. Today millions of Girls and women are sufferers of RTI and its complications, often the infection may transmit to the offspring of the pregnant mother. If adolescent girls are made aware of menstrual hygiene and reproductive health right from the early adolescent period through compulsory sex education in school curriculum, educational television programmes, and knowledgeable parents, the menarche will not shock for them and they will also be better equipped to cope up with the situation and lead to healthy life to them.

\section{ACKNOWLEDGEMENTS}

The authors are thankful to Dean Sir of GMERS Medical College, Valsad for permitting us to conduct this study in this Institute. We are also thankful to female paramedical staff for their active involvement and medical students of this institute for participation in the study.

\section{Funding: No funding sources}

Conflict of interest: None declared

Ethical approval: The study was approved by the Institutional Ethics Committee

\section{REFERENCES}

1. UNICEF-The State of World's Children Adolescence: An age of opportunity; 2011:23. Available from: http://www.unicef.org/adolescence/files/SOWC_201 1_Main_Report_EN_02092011.pdf

2. Lawan UM, Yusuf NW, Musa AB. Menstruation and menstrual hygiene amongst adolescent school girls in Kano, northwestern Nigeria, African journal of reproductive health. 2010;14(3):201-8.

3. Dasgupta A, Sarkar M. Menstrual hygiene: How hygiene is the adolescent girl? IJCM. 2008;33(2):7780 .

4. Dhingra R, Kumar A. Knowledge and practices related to menstruation among tribal (Gujjar) adolescent girls. Etho-Med. 2009;3:43-8.

5. Juyal R, Kandpal SD, Semwal J, Negi KS. Practice of menstrual hygiene among adolescent girls in a District of Uttarakhand. I J of Com Hea. 2012;24(2).

6. Khanna A, Goyal RS, Bhawsar R. Menstrual practices and reproductive problems: A study of adolescent girls in Rajasthan. J Health Manage. 2005;7:91-7.

7. Gupta S, Sinha A. Awareness about reproduction and adolescent changes among school girls of different socioeconomic status. J Obstet Gynecol. India. 2006;56(4):324-8.

8. Neamat A, Maher S, Nadia H, Eman R. Assessment of dysmenorrhea and menstrual hygiene practices among adolescent girls in some nursing schools at EL-Minia governorate, Egypt. J Am Sci. 2011;7(9):216-23.

9. Mohamed M. Epidemiology of dysmenorrhea among adolescent students in Assiut City, Egypt. Life Sci J. 2012;9(1):348-53. 
10. El-Gilanya A, Badawi K, EL-Fedawyb S. Menstrual hygiene among adolescent school girls in Mansoura, Egypt. Reproductive Health Matters. 2005;13:14752.

11. Sharma N, Sharma P, Sharma N, Wavare RR, Gautam B, Sharma M. A cross sectional study of knowledge, attitude and practices of menstrual hygiene among medical students in north India, The Journal of Phytopharmacology. 2013;2(5):28-37.

12. Patel R, Kubde S. Comparative study on menstrual hygiene in rural and urban adolescent, International Journal of Medical Science and public health. 2014;39(2):129-31.

13. Katiyar K, Chopra H, Garg SK. KAP study of menstrual problems in adolescent females in an urban area of Meerut. Indian J Community Health. 2013;25(3):217-20.

14. Nayak S, Toppo NA, Tomar SP, Kasar PK, Tiwari R. A study on practices regarding menstrual hygiene among adolescent girls of urban areas of Jabalpur District. Int $\mathrm{J}$ of Med Sci and Pub Heal. 2016;5(11):1-3.

15. Thakre SB, Thakre SS, Reddy M. Menstrual hygiene: knowledge and practice among adolescent school girls of Saoner, Nagpur district. J of Cli and Dia Res. 2011;5(5):1027-33.

16. Bhattacharyya M, Sen P, Hazara S, Sinha R, Sahoo S. A study of Menstrual Hygiene among adolescent school girls in a slum area of Kolkata, National Journal of Community Medicine. 2016;6(2):345-8.

17. Adhikari P, Kadel B, Dhungel SI. Knowledge and practice regarding menstrual hygiene in rural adolescent girls of Nepal. Kathmandu Univ Med J. (KUMJ). 2007 Jul-Sep;5(3):382-6.

18. Ziade FM, Neheme M. Assessment of beliefs and prac-tices relating to menstrual hygiene of adolescent girls in Labanon. IJHSR. 2013;3(12):75-88.

19. Arumugam B, Nagalingam S, Varman PM. Menstrual hygiene practices: is it practically impractical. Int J Med Public Health. 2014;4(4):472-6.

20. Kavitha VRS. Reproductive health and hygiene among adolescents. http:/www language in India. 2012;12(2):293-300. Accessed on $4^{\text {th }}$ April 2015.

Cite this article as: Patel HR, Patel RR. A cross sectional study on menstruation and menstrual hygiene among medical students of Valsad, Gujarat. Int J Reprod Contracept Obstet Gynecol 2016;5:4297-302. 